\title{
Trypanosoma cruzi: Impact of dual-clone infections on parasite biological properties in $\mathrm{BALB} / \mathrm{c}$ mice
}

\author{
H.R. Martins ${ }^{\text {a }}$, M.J.O. Toledo ${ }^{\text {b }}$, V.M. Veloso ${ }^{\text {c }}$, C.M. Carneiro ${ }^{\text {a,d }}$, G.L.L. Machado-Coelho ${ }^{\text {e, }}$ \\ W.L. Tafuri ${ }^{\text {a }}$, M.T. Bahia ${ }^{\text {c }}$, H.M. Valadares ${ }^{f}$, A.M. Macedo ${ }^{f}$, M. Lana ${ }^{\text {a,d,* }}$ \\ ${ }^{a}$ Núcleo de Pesquisas em Ciências Biológicas (NUPEB), Instituto de Ciências Exatas e Biológicas (ICEB), UFOP, MG, Brazil \\ ${ }^{\mathrm{b}}$ Departamento de Análises Clínicas, Universidade Estadual de Maringá, PR, Brazil \\ ${ }^{\mathrm{c}}$ Departamento de Ciências Biológicas, ICEB, UFOP, MG, Brazil \\ ${ }^{\mathrm{d}}$ Departamento de Análises Clinicas, Escola de Farmácia, Universidade Federal de Ouro Preto, Rua Costa Sena, 171, \\ CEP: 35 400-000 Ouro Preto, MG, Brazil

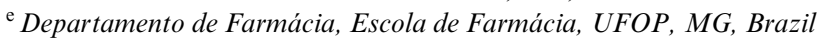 \\ ${ }^{\mathrm{f}}$ Departamento de Bioquímica e Imunologia, Instituto de Ciências Biológicas, UFOP, MG, Brazil
}

Received 8 April 2005; received in revised form 8 November 2005; accepted 10 November 2005

Available online 9 January 2006

\begin{abstract}
Herein, we have analyzed major biological properties following dual-clone Trypanosoma cruzi infections in BALB/c mice. Eight $T$. cruzi clonal stocks, two of each principal genotype, including genotype 19 and 20 (T. cruzi I), hybrid genotype 39 (T. cruzi) and 32 (T. cruzi II) were combined into 24 different dual-clone infections. Special attention was given to characterize biological parameters assayed including: prepatent period, patent period, maximum of parasitemia, day of maximum parasitemia, area under the parasitemia curve, infectivity, mortality, and hemoculture positivity. Our findings clearly demonstrated that features resultant of dual-clone infections of $T$. cruzi clonal stocks did not display either the characteristics of the corresponding monoclonal infections or the theoretical mixture based on the respective monoclonal infections. Significant changes in the expected values were observed in $4.2-79.2 \%$ of the mixtures considering the eight biological parameters studied. A lower frequency of significant differences was found for mixtures composed by phylogenetically distant clonal stocks. Altogether, our data support our hypothesis that mixed T. cruzi infections have a great impact on the biological properties of the parasite in the host and re-emphasizes the importance of considering the possible occurrence of natural mixed infections in humans and their consequences on the biological aspects of ongoing Chagas' disease.

(c) 2005 Elsevier Inc. All rights reserved.

Index Descriptors and Abbreviations: Trypanosoma cruzi; Dual-clone infection; Clonal genotypes; Biological properties; PPP, prepatent period; PP, patent period; MP, maximum parasitemia; DMP, day of maximum parasitemia; PAR, area under the parasitemia curve; INF, infectivity; MORT, mortality; +HEM, hemoculture positivity; MW, Mann-Whitney test; KS, Kolmogorov-Smirnov test; $\chi^{2}$, chi-square test; SD, number of significant differences; S, significant difference at $P<0.05$; NS, nonsignificant difference at $P>0.05$; NR, not recorded due to subpatent parasitemia; I, increased parasitemia; D, decreased parasitemia; $n$, numbers of animals
\end{abstract}

\section{Introduction}

Trypanosoma cruzi, the etiological agent of Chagas' disease, is a protozoan parasite that displays extremely heterogeneous biological properties (Andrade, 1976; Toledo et al.,

\footnotetext{
${ }^{*}$ Corresponding author. Fax: +55 3135591680.

E-mail address: delana@nupeb.ufop.br (M. Lana).
}

2002), including growth kinetics in cellular and acellular cultures (Dvorak et al., 1980; Laurent et al., 1997; Revollo et al., 1998), tissue tropism (Diego et al., 1998; Melo and Brener, 1978), pathogenicity (Andrade and Magalhães, 1997), ability to multiply and differentiate in the insect vectors (Garcia and Dvorack, 1982; Lana et al., 1998), and susceptibility to chemotherapy (Andrade et al., 1992; Revollo et al., 1998; Toledo et al., 2003; reviewed by Toledo et al., 2004). Recently, its has been considered that the diverse 
spectrum of clinical manifestations of chronic Chagas' disease (Dias, 1992; Rassi and Luquetti, 1992) may be due, at least in part, to genetic diversity of the infecting parasites (reviewed by Macedo et al., 2004).

Tibayrenc and Ayala (1988) have demonstrated that $T$. cruzi organisms undergo predominantly clonal evolution, which should render the parasite genotype relatively stable in space and time. Using this hypothesis, they have identified 43 distinct $T$. cruzi genotypes with some of them named "principal genotypes" including genotypes 19, 20,39, and 32 , which are ubiquitous and very well studied (Tibayrenc and Brenière, 1988). The working hypothesis underlying the $T$. cruzi clonal theory is that the variation of biological and medical properties of this parasite is proportional to their phylogenetic divergence. Recently, several authors have corroborated this hypothesis when working with this set of clonal genotypes (Lana et al., 1998; Laurent et al., 1997; Revollo et al., 1998; Toledo et al., 2002, 2003).

The coexistence of mixed infections in vertebrate and invertebrate hosts had already been demonstrated in both experimental (Deane et al., 1984; Lana et al., 2000; Pinto et al., 1998, 2000) and natural situations (Brenière et al., 1985; Tibayrenc et al., 1985) and this certainly plays an important role in the determining the clinical picture of the disease. Therefore, the principal goal of the present investigation was to analyze the impact of dual-clone $T$. cruzi infections in BALB/c mice. For this purpose, we have analyzed the biological properties of 24 distinct combinations of $T$. cruzi clonal stocks $(19,20,39$, and 32) compared with both the correspondent monoclonal infections and the predicted theoretical patterns of dual-clone infections.

\section{Materials and methods}

\subsection{Parasites}

We have included for monoclonal and dual-clone infections eight standard T. cruzi clonal stock representatives of the four major clonal genotypes (Tibayrenc, 1998): 19 (Gamba cl1 and OPS21 cl1) and 20 (Cuica cl1 and P209 cl1) both from T. cruzi I; the hybrid genotype 39 (Bug2148 $\mathrm{cl}$ and $\mathrm{SO} 3 \mathrm{cl} 5$ ) and the genotype 32 (IVV cl4 and MAS cl1) from $T$. cruzi II. These stocks were previously typed with 22 enzyme loci and RAPD (Tibayrenc et al., 1993) and were chosen based on their biological properties (more and less virulent) previously observed in $\mathrm{BALB} / \mathrm{c}$ mice (Toledo et al., 2002).

\subsection{Experimental infections}

For monoclonal infections, groups of six female BALB/c mice, 28-30 days old, were intraperitoneally inoculated with 10,000 blood trypomastigotes of a given T. cruzi clonal stock. Dual-clone infection was also carried out using groups of six female BALB/c mice, 28-30 days old, intraperitoneally inoculated with two different clones, using 5000 blood trypomastigotes of each clone. The inocula were counted according to Brener (1962). Twenty-four different parasite combinations were analyzed (Table 1).

\subsection{Parameters evaluated}

Eight biological parameters were considered and included: prepatent period (PPP), patent period (PP), maximum parasitemia (MP), day of maximum parasitemia (DMP), area under the parasitemia curve (PAR), infectivity (INF), mortality (MORT), and hemoculture positivity (+HEM). The reproducibility of the different parameters for monoclonal infections was previously assayed in similar experiments with 5000 and 10,000 parasites.

Parasitemia was daily examined according to Brener (1962), starting at day 4 after inoculation. PPP and DMP for animals with subpatent parasitemia were not recorded. Infectivity (INF) was evaluated by fresh blood examination and/or hemoculture during the first month of infection and expressed as percentage of infected animals. Animals with negative results were eliminated from further analyses. Mortality (MORT) was expressed in cumulative percentage observed during 90 days following infection. Hemoculture was carried out according to the Filardi and Brener (1987), 60 days after inoculation and expressed in percentage of positive hemoculture for each group of animals.

\subsection{Statistical analysis}

The null hypothesis tested here was that "there was no interference by one clone on the major biological properties of the other one included in the mixture." The data analysis

Table 1

Combinations of representative clones of genotypes 19, 20,39, and 32 of T. cruzi used in BALB/c mice dual-clone infections

\begin{tabular}{lllll}
\hline Mixture of genotypes & Mixture of clones $^{\mathrm{a}}$ & & & \\
\cline { 2 - 5 } & + Virulent + Virulent & - Virulent - Virulent & + Virulent - Virulent & - Virulent + Virulent \\
\hline $19+20$ & Gamba cl1 + P209 cl1 & OPS21 cl11 + Cuica cl1 & Gamba cl1 + Cuica cl1 & OPS21 cl11 + P209 cl1 \\
$19+39$ & Gamba cl1 + Bug2148 cl1 & OPS21 cl11 + SO3 cl5 & Gamba cl1 + SO3 cl5 & OPS21 cl11 + Bug2148 cl1 \\
$19+32$ & Gamba cl1 + IVV cl4 & OPS21 cl11 + MAS cl1 & Gamba cl1 + MAS cl1 & OPS21 cl11 + IVV cl4 \\
$20+32$ & P209 cl1 + IVV cl4 & Cuica cl1 + MAS cl1 & P209 cl1 + MAS cl1 & Cuica cl1 + IVV c14 \\
$20+39$ & P209 cl1 + Bug2148 cl1 & Cuica cl1 + SO3 cl5 & P209 cl1 + SO3 cl5 & Cuica cl1 + Bug2148 cl1 \\
$39+32$ & Bug2148 cl1 + IVV cl4 & SO3 cl5 + MAS cl1 & Bug2148 cl1 + MAS & SO3 cl5 + IVV cl4 cl1 \\
\hline
\end{tabular}

a + virulent, clone more virulent; - virulent, clone less virulent. These clones were chosen among 20 representative clones of the four major clonal genotypes. 
was performed comparing the observed or experimental values with the expected or theoretical values based on their respective monoclonal infections.

Previous experiments of monoclonal infections showed that PPP, PP, INF, and MORT were similar for infections with inocula of 5000 and 10,000 parasites; MP and PAR were proportional to the inoculum. According to these results, the expected values for dual-clone infections were predicted for all biological parameters as follows: (a) the PPP was that observed for the clone with lower PPP; (b) the $\mathrm{PP}$ was derived from the clone with longer PP; (c1) the DMP was that for the more virulent clone, if they displayed distinct parasitemia at monoclonal infection; (c2) the DMP of the clone with earlier DMP if they displayed distinct DMP at monoclonal infection but shared similar parasitemia; (c3) the mean value of the DMP if they share similar DMP and parasitemia; (d) the mean MP was calculated from parasitemia of respective monoclonal infections detected in the DMP for theoretical mixture; (e) the mean PAR was calculated from respective PAR of monoclonal infections; and (f) INF, MORT, and +HEM were obtained from the clone with the greater values or the additive effect (sum) of the values from the monoclonal infection.

Student's $t$ test was used to compare the expected and observed results of biological parameters for dual-clone infections. One-way variance analysis (ANOVA) or MannWhitney $U$ tests were used to compare PPP, PP, MP, and DMP between monoclonal and expected and observed dual-clone infections as appropriate for parametric and nonparametric data, respectively. The Kolmogorov-Smirnov test was used to compare PAR between monoclonal, theoretical, and observed dual-clone infections. For data expressed in percentage (INF, MORT, and +HEM), the chi-square $\left(\chi^{2}\right)$ test was employed (Snedecor and Cochran, 1989). A correlation matrix between genetic distances (Jaccard's Index - Jaccard, 1908) and biological differences identified between theoretical and experimental dual-clone infections was elaborated using Statview software (SAS Institute, USA). To determine if a correlation coefficient statistically differed from zero, Fisher's transformation method from $r$ to $z$ was used. This test was also used to estimate the correlation among all biological parameters under study.

Statistically significant differences (S) were considered at $P<0.05$.

\section{Results}

The overall statistical analysis of the 24 combinations of infections with mixtures of $T$. cruzi clones showed scare significant differences in INF, MORT, and + HEM parameters when compared with expected values (Fig. 1). At the contrary, the other parameters that define the profile of the parasitemia were frequently different from the expected ones. The parameter PAR displayed the highest frequency of significant differences between expected and observed profiles. A decrease (D) in parasitemia was observed in $45.8 \%$ of dual-

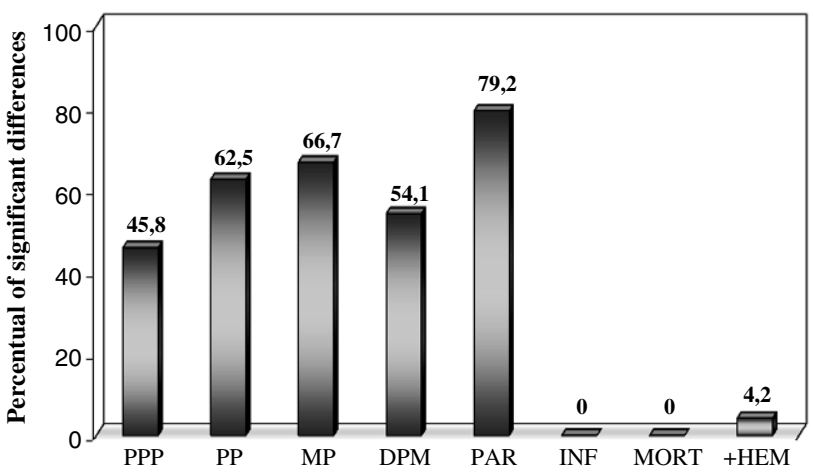

Fig. 1. Percentage of significant differences between the expected and observed data of $T$. cruzi dual-clone infections in BALB/c mice.

clone infection in comparison to the expected profiles. On the other hand, increased parasitemia (I) was observed in 37.5\% of dual-clone infections (Table 2). Examples of increased (Figs. 2A and B), decreased (Figs. 3A and B), and nonsignificant differences (Figs. 4A and B) for PAR between expected and observed values are shown in representative graphs. A complete and reciprocal inhibition of one clone over another was observed for the dual-clone infection with OPS21 cl11 + SO3 cl5 (Fig. 3B). In this case, parasites could not be recovered by hemoculture as described by Filardi and Brener (1987) and the persistence of the infection could only be confirmed after repeated fresh blood examination (up to six samples of $5 \mu \mathrm{l}$ of blood). Indeed, for the mixture OPS21 cl11+SO3 c15, the PPP and DPM could not be recorded $(\mathrm{NR})$ and the expected data $(\mathrm{PPP}=10.0 \pm 3.2$ and $\mathrm{DPM}=31.2 \pm 8.0$ ) are very different from the observed. Similar results were also observed for the dual-clone infection with $\mathrm{SO} 3 \mathrm{cl} 5+\mathrm{MAS}$ cl11 (expected values: $\mathrm{PPP}=8.9 \pm 1.4$ and $\mathrm{DPM}=15.4 \pm 4.6$ ).

We could not identify a very clear association between increase or decrease in parasitemia and specific $T$. cruzi genotype combinations. The Fisher's test showed no correlation between genetic distances between each clone (Jaccard's Index) and the differences between the expected and observed values for all parameters assayed, except for PAR where a negative weak correlation $(r=-0.454)$ was observed.

Nonsignificant differences were observed for INF and MORT between the expected and observed values for dualclone infections (Table 3, Fig. 1). Regarding the MORT, we only detected an increase from 15.4 to $40 \%$, observed for the combination OPS21 cl11+ P209 cl1 and a decrease in the majority of the mixtures involving P209 cll + genotype 39 or P209 cl1 + genotype 32. However, these differences were not significant due to the small number of animals used for each group.

Decreased +HEM was observed for the mixture OPS21 $\mathrm{cl} 11+\mathrm{SO} 3 \mathrm{cl} 5(P<0.05)$ when compared with the monoclonal and theoretical dual-clone infections. For the other four mixtures (OPS21 cl11+ IVV cl4, Gamba cl1 + MAS cl1, IVV cl4 + Bug2148 cl1, and IVVcl4 + SO3 cl5), slight but nonsignificant decreases on +HEM were observed. 
Table 2

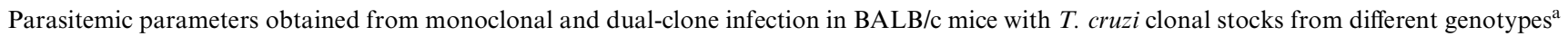

\begin{tabular}{|c|c|c|c|c|c|c|c|}
\hline Genotypes & Clones & PPP (days) & PP (days) & $\mathrm{MP}\left(\times 10^{3}\right)$ & DMP (days) & $\operatorname{PAR}\left(\times 10^{3}\right)$ & $\mathrm{SD}$ \\
\hline 19 & Gamba cl1 & $19.4 \pm 6.37$ & $54.4 \pm 11.68$ & $31.4 \pm 18.80$ & $52.8 \pm 15.30$ & & \\
\hline 19 & OPS21 cl11 & $16.4 \pm 4.90$ & $23.0 \pm 6.40$ & $11.0 \pm 8.12$ & $31.2 \pm 7.99$ & & \\
\hline 20 & Cuica cll & $20.0 \pm 7.07$ & $11.2 \pm 12,50$ & $9.8 \pm .6 .34$ & $24.00 \pm 5,92$ & & \\
\hline 20 & P209 cl1 & $9.6 \pm 3.97$ & $58.1 \pm 15.15$ & $73.9 \pm 52.71$ & $26.4 \pm 7.96$ & & \\
\hline 39 & BUG2148 cl1 & $7.2 \pm 1.40$ & $4.1 \pm 1.63$ & $7.8 \pm 2.48$ & $8.6 \pm 1.65$ & & \\
\hline 39 & $\mathrm{SO} 3 \mathrm{cl} 5$ & $10.0 \pm 3.16$ & $1.5 \pm 2.26$ & $4.4 \pm 3.58$ & $12.0 \pm 4.40$ & & \\
\hline 32 & IVV cl4 & $14.0 \pm 3.70$ & $36.4 \pm 21.69$ & $23.2 \pm 21.63$ & $33.7 \pm 5.33$ & & \\
\hline 32 & MAS cl1 & $8.9 \pm 1.37$ & $11.3 \pm 3.20$ & $17.0 \pm 6.53$ & $15.4 \pm 4.59$ & & \\
\hline $19+20$ & Gamba cll + Cuica cll & $20.5 \pm 6.04(\mathrm{NS})$ & $79.7 \pm 9.29(\mathrm{~S})$ & $25.2 \pm 8.23(\mathrm{NS})$ & $52.2 \pm 14.37(\mathrm{NS})$ & $\mathrm{I}(\mathrm{S})$ & 2 \\
\hline $19+20$ & Gamba cl1 + P209 cl1 & $5.6 \pm 1.63(\mathrm{NS})$ & $60.6 \pm 6.90(\mathrm{NS})$ & $170.8 \pm 22.87(\mathrm{~S})$ & $30.2 \pm 4.02(\mathrm{NS})$ & $\mathrm{I}(\mathrm{S})$ & 2 \\
\hline $19+20$ & OPS21 cl11 + Cuica cl1 & $10.9 \pm 2.64(\mathrm{~S})$ & $56.0 \pm 6.91(\mathrm{~S})$ & $35.0 \pm 14.39(\mathrm{~S})$ & $38.1 \pm 8.13(\mathrm{~S})$ & $\mathrm{I}(\mathrm{S})$ & 5 \\
\hline $19+20$ & OPS21 cl11 + P209 cl1 & $11.1 \pm 3.08(\mathrm{NS})$ & $41.4 \pm 14.62(\mathrm{NS})$ & $17.5 \pm 5.59(\mathrm{~S})$ & $36.4 \pm 10.83(\mathrm{NS})$ & $\mathrm{D}(\mathrm{S})$ & 2 \\
\hline $19+39$ & Gamba cl1 + Bug2148 cll & $11.8 \pm 2.64(\mathrm{~S})$ & $68.2 \pm 4.32(\mathrm{~S})$ & $56.0 \pm 19.49(\mathrm{~S})$ & $42.0 \pm 7.78(\mathrm{~S})$ & $\mathrm{I}(\mathrm{S})$ & 5 \\
\hline $19+39$ & Gamba cl1 + SO3 cl5 & $11.6 \pm 2.43(\mathrm{NS})$ & $88.7 \pm 4.32(\mathrm{~S})$ & $22.0 \pm 5.32(\mathrm{~S})$ & $47.0 \pm 17.34(\mathrm{NS})$ & (NS) & 2 \\
\hline $19+39$ & OPS21 cl11 + Bug2148 cl1 & $10.6 \pm 2.40(\mathrm{~S})$ & $60.6 \pm 6.48(\mathrm{~S})$ & $19.4 \pm 7.29(\mathrm{~S})$ & $23.2 \pm 10.86(\mathrm{~S})$ & $\mathrm{I}(\mathrm{S})$ & 5 \\
\hline $19+39$ & OPS21 cl11 + SO3 cl5 & NR (S) & $0.1 \pm 0.33(\mathrm{~S})$ & $0.5 \pm 1.67(\mathrm{~S})$ & NR $(S)$ & $\mathrm{D}(\mathrm{S})$ & 5 \\
\hline $19+32$ & Gamba cl1 + IVV cl4 & $6.6 \pm 2.45(\mathrm{~S})$ & $56.5 \pm 9.81(\mathrm{NS})$ & $29.0 \pm 8.29(\mathrm{NS})$ & $52.3 \pm 4.32(\mathrm{NS})$ & $\mathrm{D}(\mathrm{S})$ & 2 \\
\hline $19+32$ & Gambá cl1 + MAS cll & $15.4 \pm 6.27(\mathrm{~S})$ & $54.4 \pm 5.94(\mathrm{NS})$ & $30.0 \pm 24.24(\mathrm{NS})$ & $44.6 \pm 13.67(\mathrm{NS})$ & (NS) & 1 \\
\hline $19+32$ & OPS21 cl11 + IVV cl4 & $10.3 \pm 4.60(\mathrm{NS})$ & $1.8 \pm 2.39(\mathrm{~S})$ & $3.8 \pm 2.17(\mathrm{~S})$ & $11.7 \pm 5.50(\mathrm{~S})$ & $\mathrm{D}(\mathrm{S})$ & 4 \\
\hline $19+32$ & OPS21 cl11 + MAS cl1 & $7.2 \pm 3.27(\mathrm{NS})$ & $1.3 \pm 1.03(\mathrm{~S})$ & $4.2 \pm 2.04(\mathrm{~S})$ & $8.2 \pm 3.27(\mathrm{~S})$ & $\mathrm{D}(\mathrm{S})$ & 4 \\
\hline $20+39$ & Cuica cl1 + Bug2148 cl1 & $12.7 \pm 5.78(\mathrm{~S})$ & $48.0 \pm 5.29(\mathrm{~S})$ & $69.2 \pm 26.72(\mathrm{~S})$ & $40.5 \pm 4.89(\mathrm{~S})$ & $\mathrm{I}(\mathrm{S})$ & 5 \\
\hline $20+39$ & Cuíca cl1 + SO3 cl5 & $11.0 \pm 2.93(\mathrm{~S})$ & $88.9 \pm 9.15(\mathrm{~S})$ & $35.0 \pm 6.64(\mathrm{~S})$ & $44.3 \pm 11.51(\mathrm{~S})$ & $\mathrm{I}(\mathrm{S})$ & 5 \\
\hline $20+39$ & P209 cl1 + Bug2148 cl1 & $11.1 \pm 3.94(\mathrm{~S})$ & $48.8 \pm 4.97(\mathrm{NS})$ & $38.6 \pm 17.74(\mathrm{NS})$ & $30.8 \pm 8.44(\mathrm{NS})$ & (NS) & 1 \\
\hline $20+39$ & $\mathrm{P} 209 \mathrm{cl}+\mathrm{SO} 3 \mathrm{cl} 5$ & $10.2 \pm 1.98(\mathrm{NS})$ & $72.2 \pm 5.19(\mathrm{NS})$ & $41.8 \pm 20.64(\mathrm{NS})$ & $29.2 \pm 11.27(\mathrm{NS})$ & (NS) & 1 \\
\hline $20+32$ & Cuica cl1 + IVV cl4 & $6.3 \pm 1.86(\mathrm{~S})$ & $70.7 \pm 8.60(\mathrm{NS})$ & $20.8 \pm 6.64(\mathrm{NS})$ & $33.3 \pm 16.54(\mathrm{NS})$ & (NS) & 1 \\
\hline $20+32$ & Cuica cl1 + MAS cl1 & $7.0 \pm 2.67(\mathrm{NS})$ & $49.2 \pm 11.99(\mathrm{~S})$ & $10.8 \pm 3.76(\mathrm{NS})$ & $14.3 \pm 4.76(\mathrm{NS})$ & $\mathrm{I}(\mathrm{S})$ & 2 \\
\hline $20+32$ & P209 cl1 + IVV cl4 & $7.6 \pm 1.30(\mathrm{NS})$ & $61.8 \pm 14.69(\mathrm{NS})$ & $35.5 \pm 17.82(\mathrm{NS})$ & $36.5 \pm 9.71(\mathrm{NS})$ & $\mathrm{D}(\mathrm{S})$ & 1 \\
\hline $20+32$ & P209 cl1 + MAS cl1 & $6.9 \pm 2.80(\mathrm{NS})$ & $54.3 \pm 8.89(\mathrm{NS})$ & $10.0 \pm 0.00(\mathrm{~S})$ & $51.2 \pm 14.96(\mathrm{~S})$ & $\mathrm{D}(\mathrm{S})$ & 3 \\
\hline $39+32$ & Bug2148 cl1 + MAS cl1 & $9.2 \pm 1.92(\mathrm{NS})$ & $1.8 \pm 1.83(\mathrm{~S})$ & $4.2 \pm 2.04(\mathrm{~S})$ & $11.8 \pm 1.80(\mathrm{~S})$ & $\mathrm{D}(\mathrm{S})$ & 4 \\
\hline $39+32$ & SO3 cl5 + MAS cl1 & NR (S) & $0.33 \pm 0.51(\mathrm{~S})$ & $1.7 \pm 2.58(\mathrm{~S})$ & NR (S) & $\mathrm{D}(\mathrm{S})$ & 5 \\
\hline $39+32$ & Bug2148 cl1 + IVV cl4 & $7.4 \pm 1.41(\mathrm{NS})$ & $3.2 \pm 2.64(\mathrm{~S})$ & $6.7 \pm 2.58(\mathrm{~S})$ & $8.3 \pm 1.63(\mathrm{~S})$ & $\mathrm{D}(\mathrm{S})$ & 4 \\
\hline $39+32$ & $\mathrm{SO} 3 \mathrm{cl} 5+\mathrm{IVV} \mathrm{cl} 4$ & $8.7 \pm 3.15(\mathrm{NS})$ & $3.83 \pm 3.54(\mathrm{~S})$ & $5.3 \pm 3.44(\mathrm{~S})$ & $11.2 \pm 2.05(\mathrm{~S})$ & $\mathrm{D}(\mathrm{S})$ & 4 \\
\hline$\%$ of SD (total of SD) & & $45.8(11)$ & $62.5(15)$ & $66.7(16)$ & $54.1(13)$ & $79.2(19)$ & $61.7(74)$ \\
\hline
\end{tabular}

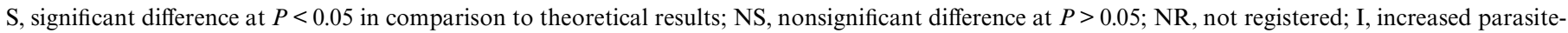
mia; D, decreased parasitemia; SD, number of significant differences.

a Student's $t$ test was used to compare PPP, PP, MP, and DMP. Kolmogorov-Sminorv test was used to compare PAR.

We only observed two positive correlation ( $r$ statistically different from zero) among the biological parameters, PAR $\times$ PM $(r=0.979)$ and DPM $\times+$ HEM $(r=0.446)$.

Taken together, our findings demonstrated significant differences in $4.2-79.2 \%$ of the mixtures depending of parameter assayed $(4.2 \%$ for +HEM, $45.83 \%$ for PPP, $62.5 \%$ for PP, $66.6 \%$ for MP, and $54.1 \%$ for DMP). When all parameters were considered together, 11 significant differences were detected for the genotype combination $(19+20), 18$ for $(19+39), 11$ for $(19+32), 11$ for $(20+39), 7$ for $(20+32)$, and 15 for $(39+32)$ between the expected and observed values for the dual-clone infections (Fig. 5).

\section{Discussion}

The natural populations of $T$. cruzi species display a high genetic polymorphism, demonstrated by different molecular markers including isoenzymes (Miles et al., 1977; Tibayrenc and Ayala, 1988), RAPD (Steindel et al., 1993; Tibayrenc et al., 1993), RFLP of the kDNA (Morel et al., 1980), minisatellites (Macedo et al., 1992), microsatellites
(Oliveira et al., 1997), and polymorphism of rRNA genes and mini-exons (Souto et al., 1996).

Tibayrenc and Ayala (1988) have suggested that this polymorphism is a consequence of long-term clonal evolution with occasional genetic exchange. The cumulative evolutionary divergence among $T$. cruzi clones involves genes that regulate important parasite properties relating to virulence, pathogenicity, and Chagas' disease morbidity and epidemiology. In this context, a link between genetic divergence and biological features among $T$. cruzi natural clones may be predicted. This hypothesis has been supported by several investigations demonstrating a strong linkage between genetic distances and biological properties of $T$. cruzi clonal stocks. These studies have been focused mainly on data generated from cellular and acellular in vitro cultures (Laurent et al., 1997; Revollo et al., 1998), behavior in vectors (Lana et al., 1998), biological features in mice (Diego et al., 1998; Laurent et al., 1997; Toledo et al., 2002) as well as susceptibility to benznidazole, nifurtimox, and itraconazole "in vitro" (Revollo et al., 1998) and "in vivo" (Toledo et al., 2003, 2004). 


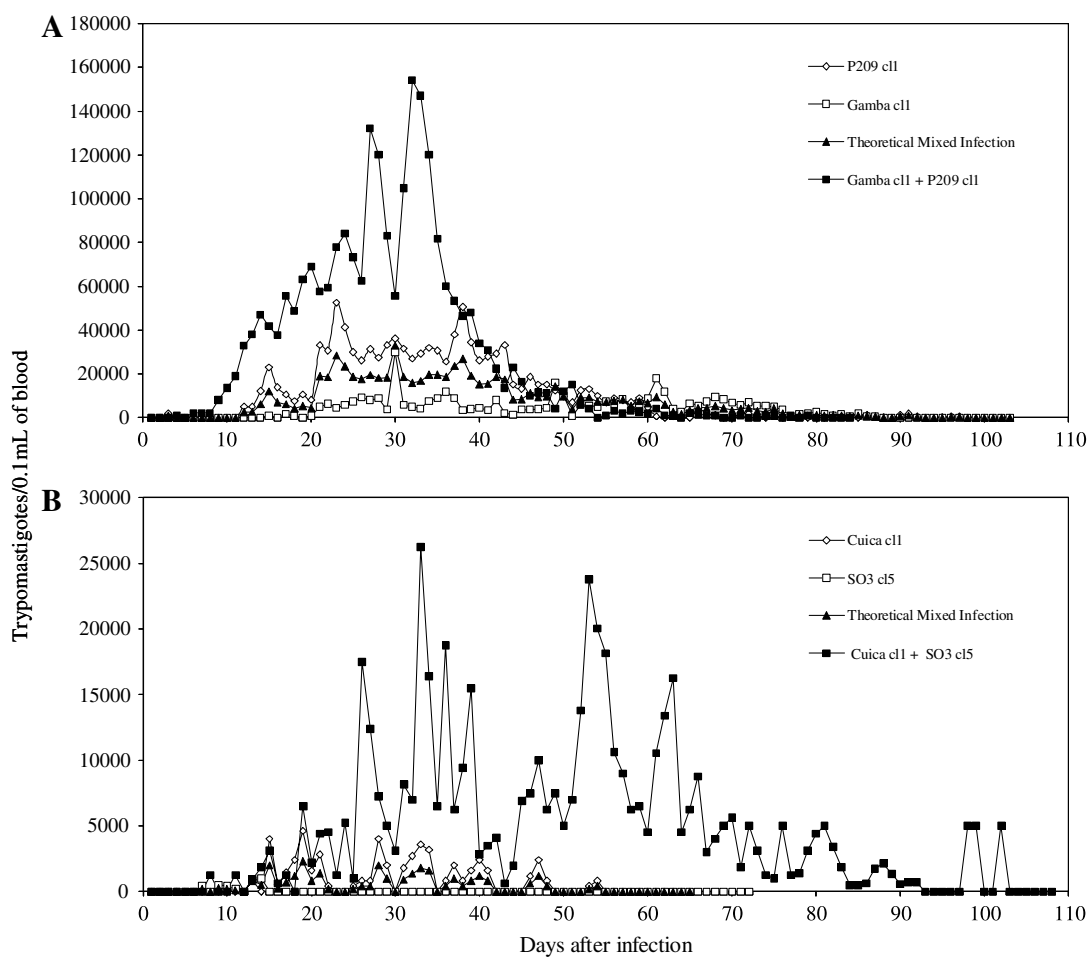

Fig. 2. Parasitemia curves of monoclonal and dual-clone T. cruzi infected BALB/c mice showing significant increase of parasitemia between expected and observed profiles for dual-clone infection (A and B). Data are expressed as mean parasitemia values.

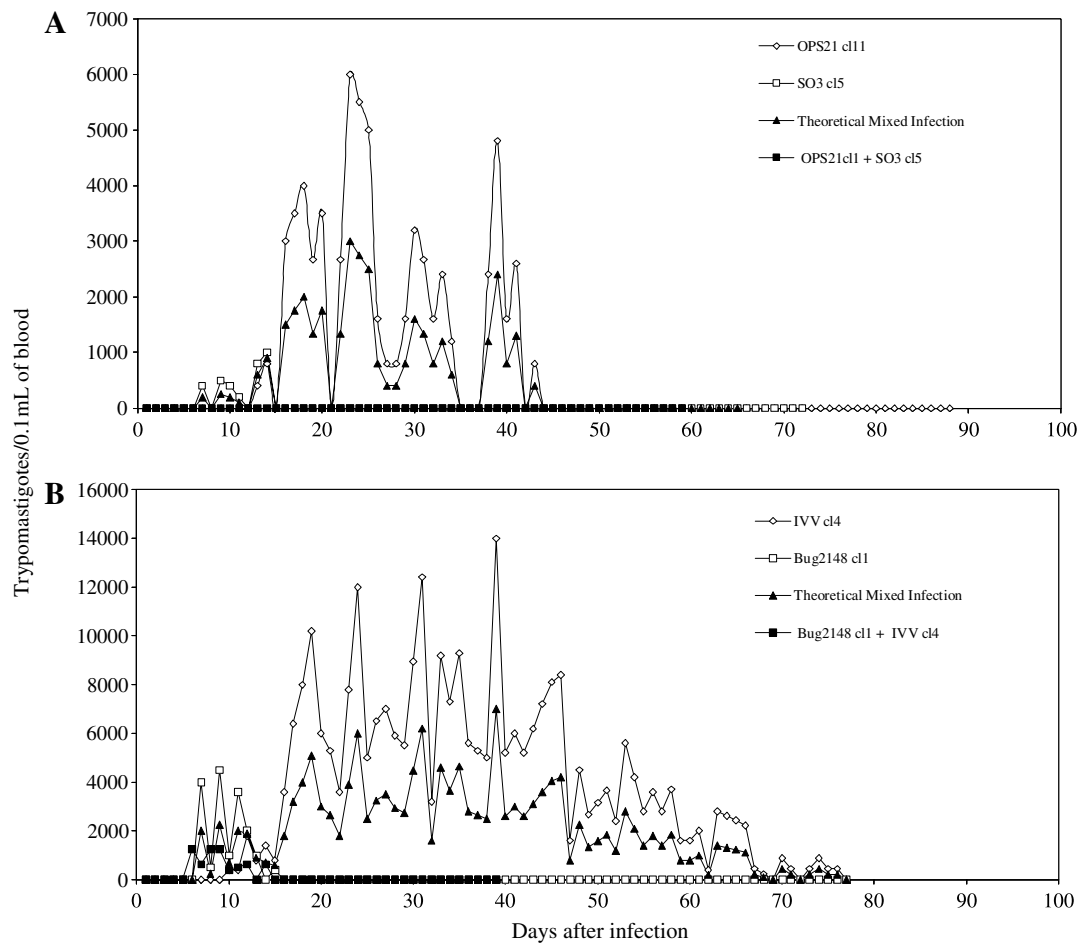

Fig. 3. Parasitemia curves of monoclonal and dual-clone T. cruzi infected BALB/c mice showing significant decrease of parasitemia between expected and observed profiles for dual-clone infection (A and B) and complete inhibition (B). Data are expressed as mean parasitemia values.

Natural populations of the T. cruzi are genetically heterogeneous with different biological properties that could interact resulting in parasites with new properties more adapted to develop into the host (Lauria-Pires and Teixeira, 1996) or culture conditions (Finley and Dvorak, 1987; Lauria-Pires et al., 1997). Experimental mixed infections in vectors, mice, 


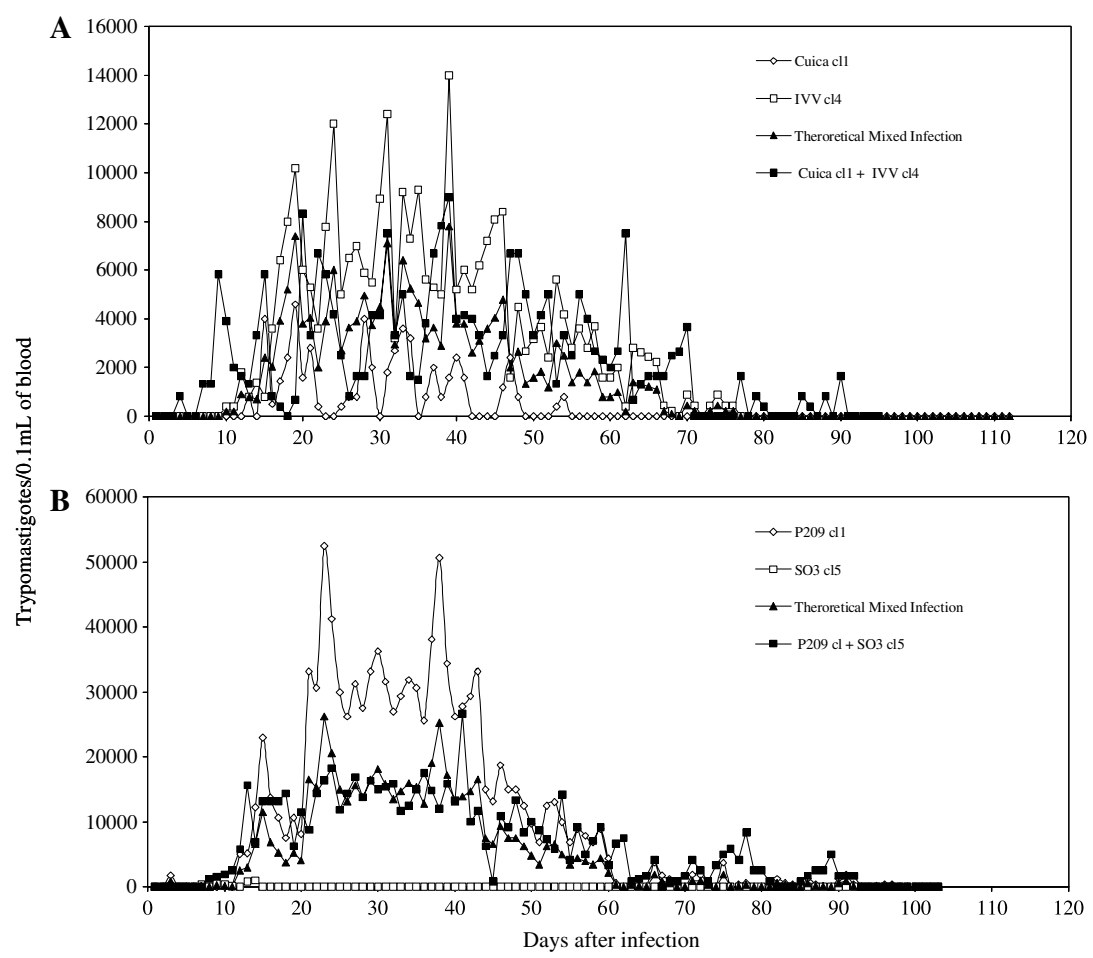

Fig. 4. Parasitemia curves of monoclonal and dual-clone $T$. cruzi infected BALB/c mice showing nonsignificant differences between expected and observed profiles for dual-clone infection (A and B). Data are expressed as mean parasitemia values.

and rats have also confirmed this phenomenon (Franco et al., 2003; Lana et al., 2000; Pinto et al., 1998). Similar findings were previously obtained by Finley and Dvorak (1987) when studying $T$. cruzi development in cellular and acellular cultures. These authors proposed a mathematical model to represent the growth dynamic of the clones in the mixture, in which the faster one tends to dominate, with disappearance of the slower one. Pinto et al. (1998) have also investigated the interactions between $T$. cruzi clonal stocks from different genotypes, suggestive of reciprocal stimulation or inhibition in experimental Triatoma infestans infections. Similar results were obtained by Lana et al. (1998) studying mixed and monoclonal infections with some of these clonal stocks in $\mathrm{BALB} / \mathrm{c}$ mice. In addition, interactions between different $T$. cruzi clones with distinct behaviors have been observed in mixed infections in mice and rats (Deane et al., 1984; Franco et al., 2003). These authors observed that previous infection with the less virulent population prevented the animals of developing a severe acute phase and mortality. Franco et al. (2003) also showed that the surviving animals displayed different tissue tropisms and lesions than those seen in single infections.

This suggests that natural mixed infections (Bosseno et al., 2000; Solari et al., 2001) might be an important factor affecting the biological properties of the parasite in infected hosts with consequences for disease morbidity and the dynamic of parasite transmission (Buscaglia and Di Noia, 2003; Pinto et al., 2000).

Many studies have failed to correlate the genetic variability of the parasite with the clinical manifestations of human Chagas' disease and the therapeutic response. One possible explanation is the selection of sub-populations during the parasite isolation and growth in culture before genetic characterization (Deane et al., 1984; Lauria-Pires et al., 1997). However, our data suggest that the interaction between clones in mixed infections may result in significant changes in host-parasite relationship. The characterization of $T$. cruzi sub-populations isolated from patients, reservoirs, and vectors in endemic areas may reveal different patterns of genetic combination in the original population. This may permit to find better correlations with the epidemiology of the disease such as capacity for development in the vector or vertebrate host and how they can be transmitted among them; evolution of the infection, clinical manifestations of the disease, and susceptibility to chemotherapy.

The goal of the present work was to define in BALB/c mice the impact of dual-clone $T$. cruzi infections on major biological properties when compared with the correspondent theoretical mixture using distinct clonal stocks from four major $T$. cruzi genotypes.

Our findings failed to support the null hypothesis that "there was no interference of one clone on the biological properties of the other one present in the dual-clone infection." We have clearly demonstrated that dual-clone infections with $T$. cruzi clonal stocks led to important effects, differing from those predicted by the theoretical mixture based on the respective monoclonal infections. Significant changes were observed in $4.2-79.2 \%$ of dual-clone infections for all biological features analyzed. 
Table 3

Percentages of infectivity, mortality, and positive hemoculture obtained from monoclonal and dual-clone infection in BALB/c mice with $T$. cruzi clonal stocks from different genotypes ${ }^{\mathrm{a}}$

\begin{tabular}{|c|c|c|c|c|}
\hline Genotypes & Clones & INF $(\%)$ & MORT (\%) & $+\operatorname{HEM}(\%)$ \\
\hline 19 & Gamba cl1 & 93.5 & 6.5 & 100.0 \\
\hline 19 & OPS21 cl11 & 92.3 & 0.0 & 100.0 \\
\hline 20 & Cuica cll & 100.0 & 0.0 & 80.0 \\
\hline 39 & Bug2148 cl1 & 71.4 & 3.1 & 60.0 \\
\hline 39 & $\mathrm{SO} 3 \mathrm{cl} 5$ & 50.8 & 0.0 & 80.0 \\
\hline 32 & IVV cl4 & 100.0 & 3.2 & 100.0 \\
\hline $19+20$ & Gamba cl1 + P209 cl1 & 100.0 (NS) & 16.7 (NS) & $100.0(\mathrm{NS})$ \\
\hline $19+20$ & OPS21 cl11 + Cuica cl1 & 100.0 (NS) & $12.5(\mathrm{NS})$ & $100.0(\mathrm{NS})$ \\
\hline $19+20$ & OPS21 cl11 + P209 cl1 & 100.0 (NS) & 40.0 (NS) & $100.0(\mathrm{NS})$ \\
\hline $19+39$ & Gamba cl1 + Bug2148 cl1 & 100.0 (NS) & $0.0(\mathrm{NS})$ & 100.0 (NS) \\
\hline $19+39$ & Gamba cl1 + SO3 cl5 & 100.0 (NS) & $0.0(\mathrm{NS})$ & $100.0(\mathrm{NS})$ \\
\hline $19+39$ & OPS21 cl11 + Bug2148 cl1 & 100.0 (NS) & $0.0(\mathrm{NS})$ & 87.5 (NS) \\
\hline $19+32$ & OPS 21 cl11 + MAS cl1 & $100.0(\mathrm{NS})$ & $0.0(\mathrm{NS})$ & 83.3 (NS) \\
\hline $20+39$ & Cuica cl1 + Bug2148 cl1 & 100.0 (NS) & $0.0(\mathrm{NS})$ & $100.0(\mathrm{NS})$ \\
\hline $20+39$ & Cuica cl1 + SO3 cl5 & 100.0 (NS) & 12.5 (NS) & $100.0(\mathrm{NS})$ \\
\hline $20+39$ & P209 cl1 + Bug2148 cll & 100.0 (NS) & 16.7 (NS) & $100.0(\mathrm{NS})$ \\
\hline $20+39$ & $\mathrm{P} 209 \mathrm{cl}+\mathrm{SO} 3 \mathrm{cl} 5$ & $100.0(\mathrm{NS})$ & $0.0(\mathrm{NS})$ & $100.0(\mathrm{NS})$ \\
\hline $20+32$ & Cuica cl1 + IVV cl4 & $100.0(\mathrm{NS})$ & $0.0(\mathrm{NS})$ & $100.0(\mathrm{NS})$ \\
\hline $20+32$ & Cuica cl1 + MAS cll & $100.0(\mathrm{NS})$ & $0.0(\mathrm{NS})$ & $100.0(\mathrm{NS})$ \\
\hline $20+32$ & P209 cl1 + IVV cl4 & 100.0 (NS) & $0.0(\mathrm{NS})$ & $100.0(\mathrm{NS})$ \\
\hline $20+32$ & P209 cl1 + MAS cl1 & $100.0(\mathrm{NS})$ & $0.0(\mathrm{NS})$ & $100.0(\mathrm{NS})$ \\
\hline $39+32$ & Bug2148 cll + MAS cll & $100.0(\mathrm{NS})$ & $0.0(\mathrm{NS})$ & $100.0(\mathrm{NS})$ \\
\hline $39+32$ & SO3 cl5 + MAS cl1 & $100.0(\mathrm{NS})$ & $0.0(\mathrm{NS})$ & $100.0(\mathrm{NS})$ \\
\hline $39+32$ & Bug2148 cl1 + IVV cl4 & $100.0(\mathrm{NS})$ & $0.0(\mathrm{NS})$ & $50.0(\mathrm{NS})$ \\
\hline $39+32$ & $\mathrm{SO} 3 \mathrm{cl} 5+\mathrm{IVV} \mathrm{cl} 4$ & $100.0(\mathrm{NS})$ & $0.0(\mathrm{NS})$ & $60.0(\mathrm{NS})$ \\
\hline
\end{tabular}

${ }^{a}$ Chi-square test was used to compare INF, MORT, and +HEM. S, significant difference at $P<0.05$ in comparison to theoretical results; NS, nonsignificant difference at $P>0.05$.

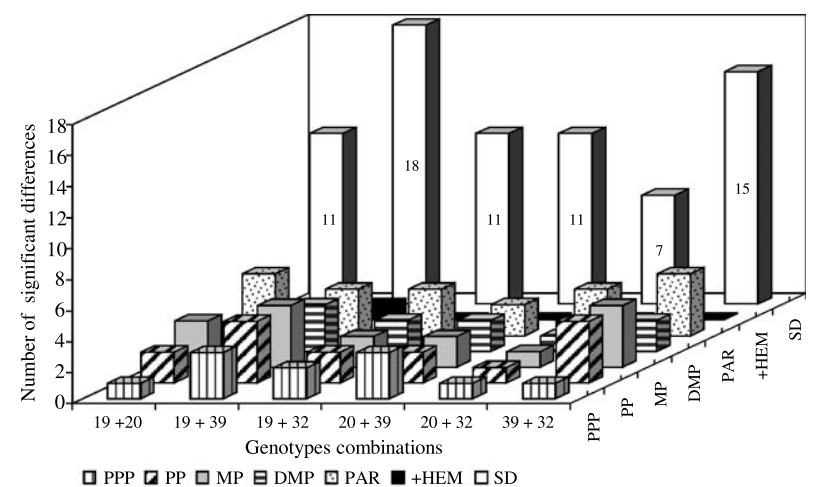

Fig. 5. Number of significant differences (SD) between expected and observed data for $T$. cruzi dual-clone infection in BALB/c mice using distinct combinations of clonal stocks from different genotypes. Data are expressed as total number of significant differences.

Parasitemia displayed the highest number of significant differences (19/24). This happened in the majority of the $T$. cruzi genotype combinations and was not related to a particular mixture. No correlation was demonstrated between genetic distances (estimated by Jaccard's Index) and the differences observed between expected and observed results. We only observed a tendency for increasing parasitemia in the dual-clone infections with clones from genotypes $19+20$ that are genetically closely related, suggesting the occurrence of a stimulatory effect between them. Another curious finding was obtained with the $32+39$ genotype combinations, also genetically closely related, that displayed inhibitory effects between the clones present in the mixtures as shown by evident decrease of parasitemia.

The majority of the clones studied here were very similar in relation to INF, MORT, and +HEM. Thus is not surprising that these parameters did not show significant differences such as observed for PAR, since it is more variable among the clones studied. Consistent with this, Franco et al. (2003) showed that MORT would be affected when studying mixed infections with $T$. cruzi populations with polar behavior regarding the mortality (lethal + nonlethal clones). Interestingly, we have observed a similar impact on MORT only for dual-clone infections with the clone P209 cll (genotype 20) and clones from the genotypes 32 and 39, 
except with Bug2148 cll (genotype 39), suggesting an inhibitory effect of genotypes 32 and 39 (lower virulence) on mortality induced by the genotype 20 (more virulent). The possibility that the small number of animals used in each experiment would be insufficient to demonstrate significant differences also needs consideration. The parameter +HEM was the only one that showed significant differences in relation to the monoclonal infections. Important but nonsignificant reductions of +HEM were observed in 5 out of 24 mixtures.

Considering that the host immune system has a very important role in parasitemia control from the start of infection (Brener and Gazzinelli, 1997) and dependent on the type of T. cruzi strain considered (Krettli and Brener, 1982), the immune response possibly plays an important role on the changes detected. Thus, the immune response induced by one clone of the mixture could interfere with the development of the other altering the biological properties of them. Moreover, it is possible that some of the properties may be more sensitive to this interference. We have noticed that although all dual-clone infections led to INF of $100 \%$, corresponding to the expected data for dual-clone infections, no additive effect was observed for MORT and +HEM. It is possible that host-related features may be involved.

Taken together, our results suggest an important interaction between the distinct clones for the majority of the mixtures and not only a juxtaposition of their characteristics. When all parameters studied were considered together, $11,18,11,11$, and 15 significant differences between expected and observed values were detected with the genotype combinations $19+20,19+39,19+32,20+39$, and $39+32$, respectively. An exception was seen with the genotype combination $20+32$. In this case, the number of significant differences was lower (only 7) than the mean difference (13) for all other genotype combinations. Interestingly, this combination includes those clones with the greatest genetic and biological distance. This suggests that interaction or competition did not occur between these clones. We did not observe any statistical correlation between the genetic distance and the differences between the expected and observed values for the mixed infections revealed by Fisher's test. Our results also re-emphasize the importance of considering the mixed infections, so frequent in the nature in animals, reservoirs, and vectors (Bosseno et al., 2000; Tibayrenc et al., 1985) as well as in humans (Brenière et al., 1985; Solari et al., 2001; Torres et al., 2003).

The development of more sensitive molecular methods that permit to characterization of $T$. cruzi populations directly from blood and tissues of host or from vector feces, have demonstrated the relevance of mixed infections in the epidemiology of Chagas' disease (Bosseno et al., 2000; Solari et al., 2001). Individuals living in endemic area are probably submitted to several re-infections that result in the different $T$. cruzi populations throughout the course of the infection (Brenière et al., 1998). However, the real impact of these mixed infections on the vertebrate host needs to be determined.
In conclusion, the present work represents an important step in knowledge of mixed infections. Interaction between the clones of the mixtures leading to changes in their biological properties and thus the course of the infection in mice has been clearly demonstrated. The factors involved in this process are not understood and open new perspectives in the knowledge of the pathogenesis and treatment of the disease. Possibly, important mechanisms relating to the modulation of immunological response (Brener and Gazzinelli, 1997; Krettli and Brener, 1982; Palau et al., 2003) through competition between the clones in mixture and changes in parasite and host gene expression could be involved (Dost et al., 2004; McDaniel and Dvorak, 1993).

\section{Acknowledgments}

We thank Dr. Michel Tibayrenc, Laboratoire de Génetique des Maladies Infectieuses, Unité Mixte de Recherche CNRS/IRD, Montpellier, France, for supplying T. cruzi clonal stocks, Dr. Christian Barnabé of this same institution for helping in statistical analysis, and Dr. Olindo Assis Martins-Filho from Centro de Pesquisa René Rachou, FIOCRUZ, Brazil, for English revision. We also thank FAPEMIG, CNPq, and WHO for financial support.

\section{References}

Andrade, S.G., 1976. Tentative for grouping different Trypanosoma cruzi strains in some types. Revista do Instituto de Medicina Tropical de São Paulo 18, 140-141.

Andrade, S.G., Magalhães, J.B., 1997. Biodemes and zymodemes of Trypanosoma cruzi strains: correlation with clinical data and experimental pathology. Revista da Sociedade Brasileira de Medicina. Tropical 30, 27-35.

Andrade, S., Rassi, A., Magalhães, J.B., Ferrioli Filho, F., Luquetti, A.O., 1992. Specific chemotherapy of Chagas' disease: a comparison between the response in patients and experimental animals inoculated with the same strains. Transactions of Royal Society Tropical Medicine and Hygiene 86, 624-626.

Bosseno, M.F., Yacsik, N., Vargas, F., Brenière, S.F., 2000. Selection of T. cruzi clonal genotypes (clonet 20 and 39) isolated from Bolivian triatomines following subculture in liquid medium. Memórias do Instituto Oswaldo Cruz 95, 601-607.

Brener, Z., 1962. Therapeutic activity and criterion of cure on mice experimentally infected with Trypanosoma cruzi. Revista do Instituto de Medicina Tropical de São Paulo 4, 389-396.

Brener, Z., Gazzinelli, R.T., 1997. Immunological control of Trypanosoma cruzi infection and pathogenesis of Chagas disease. Mini review. International Archives of Allergy and Immunology 114, 103-110.

Brenière, S.F., Tibayrenc, M., Antezana, G., Pabon, J., Carrasco, R., Selaes, H., Dejeux, P., 1985. Résultats préliminares en faveur d'une relation faible ou inexistante entre les formes cliniques de la maladie de Chagas et le souches isoenzymatiques de Trypanosoma cruzi.. Comptes Rendus de l'Academie des Sciences de Paris 300, 555-558.

Brenière, S.F., Bosseno, M.F., Telleria, J., Bastrenta, B., Yacsik, N., Noireau, F., Alcazar, J.L., Barnabé, C., Wincker, P., Tibayrenc, M., 1998. Different behavior of two T. cruzi major clones: transmission and circulation in young Bolivian patients. Experimental Parasitology 89, 285-295.

Buscaglia, C.A., Di Noia, J.M., 2003. Trypanosoma cruzi clonal diversity and the epidemiology of Chagas disease. Microbes and Infection 5, 419-427. 
Deane, M.P., Sousa, M.A., Pereira, N.M., Gonçalves, A.M., Momen, H., Morel, C.M., 1984. Trypanosoma cruzi: inoculation schedules and reisolation methods select individual strains from doubly infected mice, as demonstrated by schyzodeme and zymodeme analyses. Memórias do Instituto Oswaldo Cruz 79, 513-515.

Dias, J.C.P., 1992. Epidemiology of Chagas disease. In: Wendel, S., Brener, Z., Camargo, M.E., Rassi, A. (Eds.), Chagas Disease (American Trypanosomiasis): Its Impact on Transfusion and Clinical Medicine. ISBT, São Paulo, Brazil, pp. 49-80.

Diego, J.A., Palau, M.T., Gamallo, C., Penin, P., 1998. Relationships between histopathological findings and phylogenetic divergence in Trypanosoma cruzi. Tropical Medicine International Health 3, 222-333.

Dost, C.K., Saraiva, J., Monesi, N., Zentgraf, U., Engels, W., Albuquerque, S., 2004. Six Trypanosoma cruzi strains characterized by specific gene expression patterns. Parasitology Research 94, 134-140.

Dvorak, J.A., Hartman, D.L., Miles, M.A., 1980. Trypanosoma cruzi: correlation of growth kinetics to zymodeme type in clones derived from various sources. Journal of Protozoology 27, 472-474.

Filardi, L.S., Brener, Z., 1987. Susceptibility and natural resistance of Trypanosoma cruzi strains to drugs used clinically in Chagas disease. Transactions of Royal Society Tropical Medicine and Hygiene 81, $755-759$.

Finley, R., Dvorak, J.A., 1987. Trypanosoma cruzi: analysis of the population dynamics of heterogeneous mixtures. Journal of Protozoology 34, 409-415.

Franco, D.F., Vago, A.R., Chiari, E., Meira, F.C.A., Galvão, L.M.C., Machado, C.R.S., 2003. Trypanosoma cruzi: mixture of two populations can modify virulence and tissue and tissue tropism in rat. Experimental Parasitology 104, 54-61.

Garcia, E.S., Dvorack, J.A., 1982. Growth and development of two Trypanosoma cruzi clones in the arthropod Dipetalogaster maximus. American Journal of Tropical Medicine and Hygiene 31, 259-262.

Krettli, A.U., Brener, Z., 1982. Resistance against Trypanosoma cruzi associated to anti-live trypomastigotes antibodies. Journal of Immunology 128, 2009-2012.

Jaccard, P., 1908. Nouvelles recherches sur la distribution florale. Bulletin de la Socíée Vaudoise de Sciences Naturelles 44, 223-270.

Lana, M., Pinto, A.S., Barnabé, C., Quesney, V., Noel, S., Tibayrenc, M., 1998. Trypanosoma cruzi: compared vectorial transmissibility of three major clonal genotypes by Triatoma infestans. Experimental Parasitology $89,1-5$.

Lana, M., Pinto, A.S., Bastrenta, B., Barnabé, C., Noel, S., Tibayrenc, M., 2000. Trypanosoma cruzi: infectivity of clonal genotypes infections in acute and chronic phases in mice. Experimental Parasitology 96, 61-66.

Laurent, J.P., Barnabé, C., Quesney, V., Noel, S., Tibayrenc, M., 1997. Impact of clonal evolution on the biological diversity of Trypanosoma cruzi. Parasitology 114, 213-218.

Lauria-Pires, L., Teixeira, A.R., 1996. Virulence and pathogenicity associated with diversity of Trypanosoma cruzi stocks and clones derived from Chagas disease patients. American Journal of Tropical Medicine and Hygiene 55, 304-310.

Lauria-Pires, L., Santana, J.M., Teixeira, A.R.L, 1997. Diversity of Trypanosoma cruzi stocks and clones derived from Chagas disease patients: I-Behavior characterization "in vitro". Revista da Sociedade Brasileira de Medicina Tropical 30, 187-192.

McDaniel, J.P., Dvorak, J.A., 1993. Identification, isolation, and characterization of naturally-occurring Trypanosoma cruzi variants. Molecular Biochemistry Parasitoloqy 57, 213-222.

Macedo, A.M., Martins, M.S., Chiari, E., Pena, S.D., 1992. DNA fingerprinting of Trypanosoma cruzi: a new tool for characterization of strains and clones Molecular and. Biochemical. Parasitology 55, 147-153.

Macedo, A.M., Machado, C.R., Oliveira, R.P., Pena, S.D., 2004. Trypanosoma cruzi: genetic structure of populations and relevance of genetic variability to the pathogenesis of Chagas disease. Memórias do Instituto. Oswaldo Cruz 99, 1-11.

Melo, R.C., Brener, Z., 1978. Tissue tropism of different Trypanosoma cruzi strains. Journal of Parasitology 64, 475-482.
Miles, M.A., Toye, P.J., Oswald, S.C., Godfrey, D.G., 1977. The identification by isoenzyme patterns of two distinct strain-groups of Trypanosoma cruzi circulating independently in a rural area of Brazil. Transactions of Royal Society Tropical Medicine and Hygiene 71, 217-225.

Morel, C., Chiari, E., Camargo, E.P., Mattei, D.M., Romanha, A.J., Simpson, L., 1980. Strains and clones of Trypanosoma cruzi can be characterized by pattern of restriction endonuclease products of kinetoplast DNA minicircles. Proceedings of the National Academy of Sciences of the United States of America 77, 6810-6814.

Oliveira, R.P., Macedo, A.M., Chiari, E., Pena, S.D.J., 1997. An alternative approach to evaluating the intraspecific genetic variability of parasites. Parasitology Today 13, 196-200.

Palau, M.T., Mejia, A.J., Vergara, U., Zuniga, C.A., 2003. Action of Trypanosoma rangeli in infections with virulent Trypanosoma cruzi populations. Memórias do Instituto Oswaldo Cruz 98, 543-548.

Pinto, A.S., Lana, M., Bastrenta, B., Barnabé, C., Quesney, V., Noel, S., Tibayrenc, M., 1998. Compared vectorial transmissibility of pure and biclonal infections of Trypanosoma cruzi in Triatoma infestans. Parasitology Research 84, 348-353.

Pinto, A.S., Lana, M., Britto, C., Bastrenta, B., Tibayrenc, M., 2000. Experimental Trypanosoma cruzi biclonal infection in Triatoma infestans: detection of distinct clonal genotypes using kinetoplast DNA probes. International Journal of Parasitology 30, 843-848.

Rassi, A., Luquetti, A.O., 1992. Therapy of Chagas disease. In: Wendel, S., Brener, Z., Camargo, M.E., Rassi, A. (Eds.), Its Impact on Transfusion and Clinical Medicine. ISBT, São Paulo, Brazil, pp. 237-256.

Revollo, S., Oury, B., Laurent, J.P., Barnabé, C., Quesney, V., Carrière, V., Noel, S., Tibayrenc, M., 1998. Trypanosoma cruzi: impact of clonal evolution of the parasite on its biological and medical properties. Experimental Parasitology 89, 30-39.

Snedecor, G.W., Cochran, W.G., 1989. Statistical Methods, eighth ed. Iowa State University Press, Ames. 503 pp.

Solari, A., Campillay, R., Ortiz, S., Wallace, A., 2001. Identification of Trypanosoma cruzi genotypes circulating in Chilean chagasic patients. Experimental Parasitology 97, 226-233.

Souto, R.P., Fernandes, O., Macedo, A.M., Campbell, D.A., Zingales, B., 1996. DNA markers define two major phylogenetic lineages of Trypanosoma cruzi. Molecular and Biochemical Parasitology 83, $141-152$.

Steindel, M., Dias, N.E., De Menezes, C.L., Romanha, A.J., Simpson, A.J., 1993. Random amplified polymorphic DNA analysis of Trypanosoma cruzi strains. Molecular and Biochemical Parasitology $60,71-79$.

Tibayrenc, M., Cariou, M.L., Solignac, J.P., Dedet, J.P., Poch, O., Dejeux, P., 1985. New electrophoretic evidence of genetic variation \& diploidy in Trypanosoma cruzi, the causative agent of Chagas disease. Genetic 23, 223-225.

Tibayrenc, M., Ayala, F.J., 1988. Isozyme variability in Trypanosoma cruzi, the agent of Chagas disease: genetical, taxonomical, and epidemiological significance. Evolution 42, 277-292.

Tibayrenc, M., Brenière, S.F., 1988. Trypanosoma cruzi: major clones rather than principal zymodemes. Memórias do Instituto Oswaldo Cruz 83, 249-255.

Tibayrenc, M., Neubauer, K., Barnabé, C., Guerrine, F., Skarecky, D., Ayala, F.J., 1993. Genetic characerization of six parasitic protozoa: parity between random-primer DNA typing and multilocus enzyme electrophoresis. Proceedings of the National Academy of Sciences of the United States of America 90, 1335-1339.

Tibayrenc, M., 1998. Genetic epidemiology of parasite protozoa and other infectious agents: the need for an integrated approach. International Journal of Parasitology 28, 85-104.

Toledo, M.J.O., Lana, M., Carneiro, C.M., Bahia, M.T., Veloso, V.M., Barnabé, C., Tibayrenc, M., Tafuri, W.L., 2002. Impact of Trypanosoma cruzi clonal evolution on its biological properties in mice. Experimental Parasitology 100, 161-172.

Toledo, M.J.O., Bahia, M.T., Carneiro, C.M., Martins-Filho, O.A., Tibayrenc, M., Barnabé, C., Tafuri, W.L., Lana, M., 2003. Chemotherapy 
with benznidazole and itraconazole for mice infected with different Trypanosoma cruzi clonal genotypes. Antimicrobial Agents and Chemotherapy 47, 223-230.

Toledo, M.J.O., Tafuri, W.L., Bahia, M.T., Lana, M., 2004. A review. Genetic diversity and drug resistance in Trypanosoma cruzi, the agent of Chagas disease. Research Advances in Antimicrobial Agents Chemotherapy $4,11-22$.

Torres, J.P., Ortiz, S., Solari, A., 2003. Trypanosoma cruzi isolate from Chile are heterogeneous $\&$ composed of mixed populations when characterization by Schizodeme \& Southern analyses. Parasitology 128, 161-168. 